\title{
Intraoperative blood losses and transfusion requirements during adult liver transplantation remain difficult to predict
}

\author{
[Les pertes sanguines peropératoires et les besoins transfusionnels restent toujours \\ difficiles à prédire pendant la greffe du foie]
}

A. Steib MD,${ }^{*}$ G. Freys MD,${ }^{*}$ C. Lehmann MD,${ }^{*}$ C. Meyer MD,$\dagger$ G. Mahoudeau MD*

Purpose: To identify preoperative factors associated with high blood losses during liver transplantation for chronic end- stage liver disease.

Methods: Four hundred and ten consecutive patients were included in this retrospective study. Blood losses were calculated, based on transfusion requirements. The population was divided into two groups: the upper quartile was defined as the high blood loss $(\mathrm{HBL})$ group and the lower three quartiles as the low blood loss group. Fourteen preoperative variables were collected. Qualitative variables consisted of the type of hepatopathy, Child-Pugh's classification, sex, the surgical team's experience, previous abdominal surgery and portal hypertension. Quantitative variables were age, hemoglobin concentration $\mathrm{Hb}$, platelet count, prothrombin time, activated partial thromboplastin time, fibrinogen concentration, fibrin degradation products (FDP) and euglobulin lysis time. Univariate analysis and stepwise multivariate analysis were conducted.

Results: Patients in the $\mathrm{HBL}$ group required 12 units of red blood cell or more to maintain a $\mathrm{Hb} \geq 100 \mathrm{~g} \cdot \mathrm{L}^{-1}$. $\mathrm{HBL}$ was associated with severe liver disease, previous abdominal surgery, use of a venovenous bypass and little surgical experience in orthotopic liver transplantation (OLT). In the HBL group several hemostatic parameters were more disturbed before surgery. The multivariate analysis disclosed three independent variables associated with $\mathrm{HBL}$ : $\mathrm{Hb}$ and FDP concentrations and previous upper abdominal surgery. When combined, these resulted in a high specificity (98\%) but low sensitivity to predict blood loss.

Conclusion: Despite our efforts we were unable to identify predictive risk factors of bleeding during OLT even in a homogeneous population. Centres should evaluate their practice individually in an attempt to identify patients at high risk of being transfused.
Objectif : Découvrir les facteurs préopératoires associés à d'importantes pertes sanguines survenant pendant la greffe du foie pour maladie chronique du foie au stade ultime.

Méthode : Quatre cent dix patients successifs ont participé à une étude rétrospective. Les pertes sanguines ont été calculées d'après les besoins transfusionnels. Les participants ont été divisés en deux groupes : le quartile supérieur étant le groupe de perte sanguine élevée (PSE) et les trois quartiles inférieurs, le groupe de perte sanguine faible (PSF). Des 14 variables préopératoires rassemblées, les variables qualitatives ont été : le type d'hépatopathie, la classification de Child-Pugh, le sexe, l'expérience de l'équipe chirurgicale, les interventions abdominales antérieures et l'hypertension portale ; les variables quantitatives ont été : l'âge, le taux d'hémoglobine $(\mathrm{Hb})$, la numération plaquettaire, le temps de prothrombine, le temps de céphaline activé, la concentration en fibrinogène, les produits de dégradation de la fibrine (PDF) et le temps de lyse des euglobulines. L'analyse univariée et l'analyse multivariée séquentielle ont été réalisées.

Résultats : Les patients du groupe PSE ont eu besoin de 12 unités de globules rouges ou plus pour maintenir une $[\mathrm{Hb}] \geq 100 \mathrm{~g} \cdot \mathrm{L}^{-1}$. La PSE a été associée à: une maladie hépatique sévère, une intervention abdominale antérieure, l'utilisation d'une dérivation veino-veineuse et peu d'expérience en greffe du foie orthotopique (GFO). Dans le groupe de PSE, certains paramètres hémostatiques étaient plus instables avant l'opération. L'analyse multivariée a révélé trois variables indépendantes associées à la PSE : les concentrations d'Hb et de PDF et les interventions abdominales hautes antérieures. Les résultats combinés présentent une forte spécificité (98\%) mais une faible sensibilité à prédire les pertes sanguines.

Conclusion : Malgré nos efforts, nous n'avons pu déterminer les facteurs de risque prédictifs de saignements pendant la greffe de foie orthotopique chez une population homogène. Les hôpitaux doivent évaluer leur pratique individuelle afin de découvrir les patients à risque d'être transfusés.

From the Departments of Anaesthesia, ${ }^{*}$ and Transplantation, $\dagger$ Hôpitaux Universitaires, Strasbourg, France. Address correspondence to: Dr. Annick Steib, Departement of Anaesthesia, 1 Place de l'Hôpital, BP N 426, 67091 Strasbourg Cedex, France. Phone: 03881154 10; Fax: 03881167 60; E-mail: Annick.Steib@chru-strasbourg.fr Accepted for publication July 5, 2001. Revision accepted August 29, 2001. 
B LOOD loss represents a serious problem during orthotopic liver transplantation (OLT). Improvements in operative management, surgical techniques and graft preservation have widely contributed to a significant reduction in transfusion requirements during the last decade. ${ }^{1}$ However, blood losses remain highly variable. As the quantity of blood products required contributes to higher mortality and morbidity ${ }^{2-6}$ preoperative identification of patients at high risk of massive intraoperative hemorrhage is of great interest.

Previous attempts to recognize these patients have produced contradictory results. Most of these studies have failed to define, preoperatively, biological factors (specially those related to hemostatic disorders) predictive of hemorrhage. ${ }^{1,7-10}$ Surgical conditions such as experience of the team, use of specific coagulation devices and previous abdominal surgery have, more often, been blamed. ${ }^{1,2}$ Moreover, the majority of these trials included various types of liver disease in the patient population under study, mixing acute and chronic cases. In addition, surgical teams and transfusion protocols sometimes changed during the course of the studies. Thus, in the present report we attempted to identify demographic and preoperative factors associated with intraoperative hemorrhage and transfusion in a homogeneous group of patients with endstage chronic liver disease scheduled for OLT and managed by the same medical team.

\section{Methods}

Four hundred and ten consecutive patients suffering from chronic liver disease who received transplants in our center between January 1988 and December 1998 were included in this retrospective study. Any acute situations involving retransplantation for primary graft failure and transplantation for fulminant hepatic failure were excluded.

\section{Anesthetic procedure and monitoring}

The anesthetic procedure was standardized using a combination of thiopentone, fentanyl or sufentanil and pancuronium. Patients were ventilated with an air/oxygen/isoflurane mixture. Radial and pulmonary arterial catheters were inserted for hemodynamic measurements and blood sampling. Two iv cannulae were secured for rapid blood transfusion. Calcium chloride was administered to maintain ionized calcium concentrations between $0.9-1.2 \mathrm{mmol} \cdot \mathrm{L}^{-1}$, and sodium bicarbonate $\left(1 \mathrm{mEq} \cdot \mathrm{kg}^{-1}\right)$ was injected when base excess was below -10. Isotonic saline solution was infused at a rate of $10 \mathrm{~mL} \cdot \mathrm{kg}^{-1}$. Patients were kept warm using a heated blanket, and iv fluids were administered at a temperature of $36^{\circ} \mathrm{C}$. Initially, the surgical procedure was performed with the systematic use of a heated venovenous bypass. From 1994 onwards, the piggyback technique, not requiring cross clamping or transection of the inferior vena cava, was the preferred method. The senior anesthesiologists and surgeons involved in the procedures remained the same during the entire duration of data collection.

\section{Replacement therapy}

Packed red blood cells (RBCs) were administered to maintain hematocrit levels at $30 \%$. Fresh frozen plasma (FFP) was infused in a ratio (RBCs/FFP) of 1 to 1.5. Platelets were transfused to maintain the platelet count at around $100 \times 10^{9} \cdot \mathrm{L}^{-1}$. Cryoprecipitate was indicated when the fibrinogen level decreased below $\mathrm{lg} \cdot \mathrm{L}^{-1}$. Intraoperative salvage of blood was used in the absence of infection or cancer (Cell Saver nIV, Haemonetics Inc, Brain tree MA, USA).

A bolus of aprotinin (5000 KIU. $\left.\mathrm{kg}^{-1}\right)$ was injected systematically before revascularization. Additional boluses (200 $000 \mathrm{KIU})$ were given whenever unexplained generalized oozing occurred in the surgical field.

\section{Evaluation of intraoperative blood loss}

Intraoperative blood loss was evaluated by the quantity of RBC units required to maintain a hematocrit ratio around $30 \%$ at the end of surgery. In patients with autotransfusion, intraoperative blood loss was evaluated according to the following calculation: total $\mathrm{RBC}$ units required $=$ homologous units + autologous units. Autologous units were determined by the following formula: autologous volume transfused $\mathrm{x}$ $(0.50 / 0.75) / 250$. This adjustment was based on a hematocrit of 0.5 in autologous RBCs (compared to 0.75 in RBCs) and a mean volume of $250 \mathrm{~mL}$ in each pack of RBCs. The number of FFP and platelet units transfused during the procedure was recorded. For further analysis the population was arbitrarily divided into two groups based on total intraoperative $\mathrm{RBC}$ requirements. The upper quartile was defined as the HBL and the lower three quartiles constituted the low blood loss group (LBL). As a consequence of this arbitrary definition, the cutoff point separating the two groups was 12 RBC units.

\section{Variables}

Fourteen preoperative variables, quantitative and qualitative, were collected retrospectively. Chronic hepatopathy was divided into seven categories: alcoholic cirrhosis, chronic hepatitis, biliary cirrhosis, metabolic disease, cancer, cholangitis and cryptogenic cirrhosis. Three surgical periods were identified as relat- 
TABLE I Demographic data and blood product requirements $($ mean $\pm S D)$

\begin{tabular}{lll}
\hline & $\begin{array}{l}H B L \\
(n=110)\end{array}$ & $\begin{array}{l}L B L \\
(n=300)\end{array}$ \\
\hline Age (yr) & $48 \pm 11$ & $50 \pm 11$ \\
Weight $(\mathrm{kg})$ & $70 \pm 14$ & $71 \pm 14$ \\
Sex M/F (\%) & $68 / 32$ & $65 / 35$ \\
Duration of surgery (min) & $537 \pm 138$ & $373 \pm 102^{* * *}$ \\
RBCs (units) & $18.2 \pm 6.9$ & $5.9 \pm 2.9^{* * *}$ \\
FFP (units) & $23 \pm 9.5$ & $10.7 \pm 4.8^{* * *}$ \\
Platelets (units) & $17.8 \pm 11.7$ & $9.1 \pm 9.4^{* * *}$ \\
Aprotonin (KIU) & $507407 \pm 251984$ & $338333 \pm 153707^{* * *}$ \\
\hline
\end{tabular}

HBL=high blood loss; $\mathrm{LBL}=$ low blood loss; $\mathrm{RBC}=$ packed red blood cells; FFP=fresh frozen plasma. ${ }^{* \star *} P<0.001$.

TABLE II Preoperative biological variables

\begin{tabular}{lll}
\hline & $\begin{array}{l}\text { HBL } \\
(n=110)\end{array}$ & $\begin{array}{l}L B L \\
(n=300)\end{array}$ \\
\hline Hb beginning of operation $\left(\mathrm{g} \cdot \mathrm{L}^{-1}\right)$ & $93 \pm 17$ & $105 \pm 18^{* * *}$ \\
Hb end of operation $\left(\mathrm{g} \cdot \mathrm{L}^{-1}\right)$ & $94 \pm 16$ & $105 \pm 15^{* * *}$ \\
Platelets $\left(\mathrm{x} 10^{9} \cdot \mathrm{L}^{-1}\right)$ & $116 \pm 73$ & $132 \pm 83$ \\
Prothrombin time $(\%)$ & $51 \pm 14$ & $60 \pm 17^{* * *}$ \\
aPTT $($ ratio) & $1.4 \pm 0.4$ & $1.3 \pm 0.2$ \\
Fibrinogen $\left(\mathrm{g} \cdot \mathrm{L}^{-1}\right)$ & $2 \pm 0.8$ & $2.3 \pm 1 * * *$ \\
FDP $\left(\mathrm{mmoL} \cdot \mathrm{L}^{-1}\right)$ & $56 \pm 118$ & $25 \pm 59 * * *$ \\
ELT $(\min )$ & $106 \pm 59$ & $96 \pm 62$ \\
\hline
\end{tabular}

$\mathrm{HBL}=$ high blood loss; $\mathrm{LBL}=$ low blood loss; $\mathrm{Hb}=$ hemoglobin concentration; aPTT =activated partial thromboplastin time; FDP=fibrin degradation products; ELT=eugobulin lysis time. Prothombin time is expressed as the \% of control value (normal range: $70-100 \%)$ and aPTT is expressed as the ratio aPTTpatient/aPTT control (normal value below 1.25)

*** $P<0.001$

TABLE III Sensitivity (Se), Specificity (Sp), positive predictive value (PPV) and negative predictive value (NPV) of each putative predictor of high blood loss (HBL) and their combination.

\begin{tabular}{|c|c|c|c|c|}
\hline & Se $(\%)$ & $S p(\%)$ & $P P V(\%)$ & $N P V(\%)$ \\
\hline (A) $\mathrm{Hb}<100 \mathrm{~g} \cdot \mathrm{L}^{-1}$ & 71 & 60 & 40 & 85 \\
\hline (B) FDP $>24 \mathrm{mmoL} \cdot \mathrm{L}^{-1}$ & 57 & 71 & 43 & 81 \\
\hline $\begin{array}{l}\text { (C) Previous abdominal } \\
\text { surgery }\end{array}$ & 45 & 73 & 29 & 85 \\
\hline$(\mathrm{A})+(\mathrm{B})$ & 42 & 89 & 59 & 81 \\
\hline$(A)+(C)$ & 34 & 92 & 33 & 84 \\
\hline$(\mathrm{B})+(\mathrm{C})$ & 27 & 94 & 54 & 84 \\
\hline$(\mathrm{A})+(\mathrm{B})+(\mathrm{C})$ & 18 & 98 & 69 & 82 \\
\hline
\end{tabular}

ing to the progressive experience of the surgical team: 1988-1990 corresponded to the beginnings of hepatic transplantation, 1991-1993 was the period of maturity and 1994-1998 was a period of innovation with the introduction of the piggyback technique. Previous upper abdominal operations were recorded. ChildPugh's classification was used to assess the severity of liver disease. Preoperative portal hypertension, present in cases of ascites and/or esophageal varices, was considered as another possible risk factor. Other preoperative variables were: sex, age, hemoglobin concentration $\mathrm{Hb}$, platelet count, prothrombin time (PT), activated partial thromboplastin time (aPTT), fibrinogen concentration, fibrin degradation products (FDP) and euglobulin lysis time (ELT).

\section{Statistical analysis}

Univariate analysis was performed using a chi-square test for the comparison of discrete variables and an unpaired Student's $t$ test for the comparison of two means. Results were expressed as mean \pm SD. A $P$ value $<0.05$ was considered statistically significant. A stepwise logistic regression analysis, with blood loss representing the dependent variable, used all the variables included in the univariate analysis as independent variables. Calculations were performed by a Statview 5 program (Abacus Concepts, Inc). Sensitivity (Se), Specificity (Sp) and positive (PPV) and negative (NPV) predictive values were calculated for each isolated predictive factor and then in combination.

Results

Demographic data and blood product requirements are summarized in Table I. Figure 1 shows the distribution of RBC transfusions in the population.

There were no significant differences in age, weight and sex distribution between groups of patients. Chronic liver diseases leading to transplantation were comparable (Figure 2). Previous upper abdominal surgery was more frequent in the HBL group $(P<0.001)$. HBL was also significantly associated with surgery using a venovenous bypass ( $31 \%$ vs $13 \%$ in the piggyback technique), severe liver disease $(50 \%$ in class $\mathrm{C})$ and the period of initial surgical experience (50\% during the period 1988-1990 vs $17 \%$ in the last period) The incidence of preoperative portal hypertension was similar in both groups. Finally, Table II shows that patients with HBL were more anemic at the beginning of the procedure, had significantly increased FDP values and decreased PT (\%) and fibrinogen values before incision.

The stepwise multivariate analysis disclosed only three variables which were independently associated with intraoperative HBL: Hb, FDP values assessed before surgery and previous upper abdominal surgery. When Se, Sp, NPV and PPV were considered separately for each of these three variables, they were not of relevant clinical interest. However, when analyzed in combination, specificity increased to $98 \%$ when $\mathrm{Hb}<100 \mathrm{~g} \cdot \mathrm{L}^{-1}$, FDP $>24$ $\mathrm{mmol} \cdot \mathrm{L}^{-1}$ and previous upper abdominal surgery had been performed. 


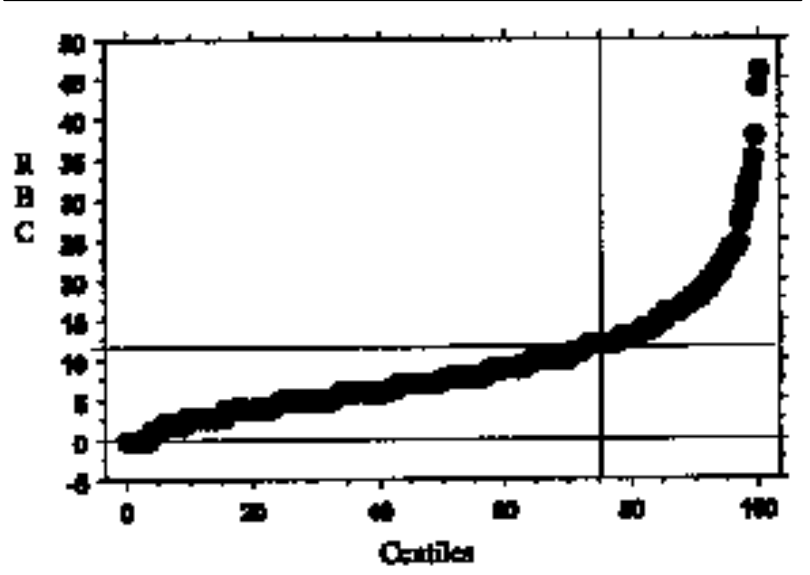

FIGURE I Percentile plot for red blood cell (RBC) requirements (units) per patient. The upper quartile represents the high blood loss group (HBL). These patients required 12 units of RBC or more to maintain hemoglobin $\geq 100 \mathrm{~g} \cdot \mathrm{L}^{-1}$.

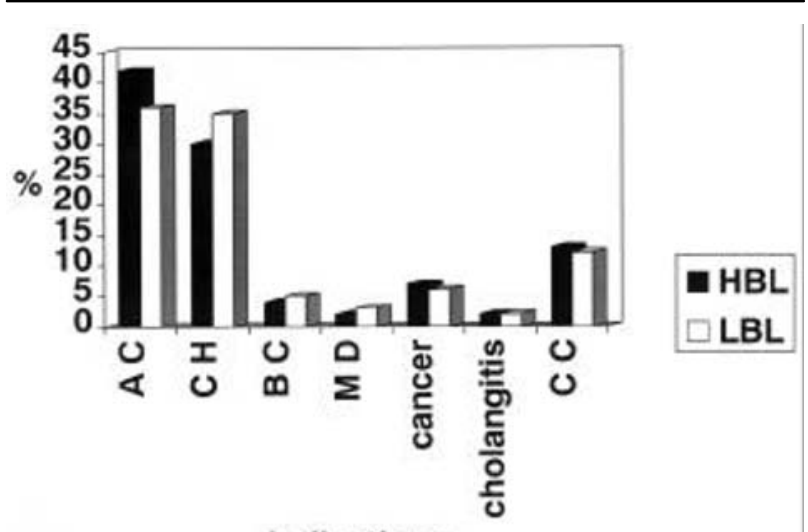

Indications

FIGURE 2 Indications for liver transplantation in both groups of patients. $\mathrm{HBL}=$ high blood loss; $\mathrm{LBL}=$ low blood loss; $\mathrm{AC}=\mathrm{alco}-$ holic cirrhosis; $\mathrm{CH}=$ chronic hepatitis; $\mathrm{BC}=$ biliary cirrhosis; $\mathrm{MD}=$ metabolic disease; $\mathrm{CC}=$ cryptogenic cirrhosis. No significant differences between groups.

Discussion

Despite recent progress in anesthetic and surgical care, severe hemorrhaging remains a problem during liver transplantation. The ability to predict intraoperative bleeding would be of great use in the global management and organization of the surgical procedure. Were this information available, the blood bank could be alerted, the most appropriate monitoring and venous access chosen, and the surgeon better prepared. ${ }^{11}$ Being able to detect the risk of perioperative hemorrhage would allow anesthesiologists to choose which patients are more likely to benefit from antifibrinolytic agents such as aprotinin, tranexamic acid or epsilon-aminocaproic acid. Although the blood sparing effect of these agents is recognized, ${ }^{12,13}$ their systematic use may be hazardous due to adverse effects such as severe allergic reactions and fatal intraoperative thromboembolism. ${ }^{14,15}$ On the other hand, the influence of transfusion on outcome and graft survival has been known for several years. ${ }^{2,4-6}$ Patients who are not transfused or receive less than five units ${ }^{4}$ have a lower morbidity and mortality. Therefore, limiting the use of blood products should improve patients' outcome. For all these reasons, several attempts have been made to identify patients with a high risk of bleeding and to define preoperative factors which could influence intraoperative bleeding. ${ }^{5,7-10}$ Results have been contradictory, mainly because of non- homogenous patient selection, surgical conditions and intraoperative management.

Our study focussed on chronic liver diseases and preoperative clotting data. Its first objective was to estimate the actual quantity of blood loss. Blood losses are very difficult to measure during liver transplantation. Most research has quantified blood losses indirectly, using blood transfusion requirements necessary to maintain or reach a trigger value. $\mathrm{Hb}$ represents the most frequent criterion for transfusion. ${ }^{11}$ In our study, the goal was to maintain a $\mathrm{Hb}$ at around $100 \mathrm{~g} \cdot \mathrm{L}^{-1}(\mathrm{Ht} \sim 30 \%$ ). The second step consisted of determining which patients could be considered to have sustained high bleeding. As in another study, ${ }^{11}$ we arbitrarily divided the population into two groups according to their intraoperative RBC requirements. The cutoff point thus obtained was approximately 12 units. Recently, a similar cutoff point was suggested by a study of $1,443 \mathrm{con}$ secutive liver transplant recipients in which patients requiring more than 12 units of RBCs intraoperatively had a significantly decreased survival rate. ${ }^{5}$

Our results revealed that previous abdominal surgery, preoperative low $\mathrm{Hb}$ and elevated FDP were specific to predict HBL. This latter factor was also identified as a predictive variable in a previous small study of cirrhotic patients who experienced severe intraoperative hyperfibrinolysis. ${ }^{7}$ Its preoperative increase may reflect an imbalance between factors promoting fibrinolysis or a low grade of disseminated intravascular coagulation. The predictive role of $\mathrm{Hb}$ found in our study was not surprising. Patients with an initial low $\mathrm{Hb}$, below $100 \mathrm{~g} \cdot \mathrm{L}^{-1}$, would require transfusion in order to reach the selected trigger point. However the difference in $\mathrm{Hb}$ between groups $(93$ vs $\left.105 \mathrm{~g} \cdot \mathrm{L}^{-1}\right)$ was insufficient to explain the large difference in RBC requirements (5.9 vs 18.2 units). 
Surgical conditions seem to play an important role. In a study of 164 recipients, ${ }^{8}$ experience of the surgical team was identified as an independent predictor of transfusion. This was not the case in our study, despite a significant decrease in the number of patients in the HBL group between the first and the third observation periods. Deakin et al., before the piggyback technique era, advocated the role of technical factors such as the use of a venovenous bypass and an argon beam coagulator, both devices contributing to the decrease of blood product requirements. ${ }^{1}$ Previous abdominal surgery was independently associated with massive transfusion in a recent report of 100 patients. $^{2}$ Our study corroborates this finding. All these results suggest that surgical conditions are related, at least to some extent, to the importance of blood loss. In particular, a history of previous abdominal surgery should make every surgeon cautious.

Another variable commonly correlated with blood loss is the severity of liver disease. Severity is assessed either globally by Child-Pugh's classification ${ }^{8}$ or, more specifically, by hemostatic data (PT, aPTT, platelets, ELT, FDP) and/or biological ${ }^{1,9}$ variables (urea, creatinin, bilirubin). However, correlation is poor and most authors have not been able to recommend specific preoperative screening tests. Surprisingly, clotting data were not independent predictors of HBL in previously published studies. $5,8,10$ The largest of these comprised 1,143 patients. $^{5}$ As has been pointed out, ${ }^{13}$ the observed discrepancies may be due to the heterogenity of the recipient population. Patients with acute and chronic liver disease are often analyzed together, blurring the results. In addition, the choice of different triggers for blood transfusions, associated to different management protocols guided or not by coagulation monitoring, with or without the use of antifibrinolytic agents, may explain these conflicting results.

Blood losses during OLT seem to vary from centre to centre. Therefore, each centre should evaluate its own practice in an attempt to identify patients requiring specific attention in the area of transfusion and the use of antifibrinolytics. In our centre, the combination of a $\mathrm{Hb}$ below $100 \mathrm{~g} \cdot \mathrm{L}^{-1}$, FDP $24 \mathrm{mmol} \cdot \mathrm{L}^{-1}$ and previous abdominal surgery is highly specific to predict HBL during OLT for chronic liver disease. Unfortunately, specificity is low, hampering our efforts to correctly identify patients at risk of intraoperative hemorrhage.

\section{References}

1 Deakin M, Gunson BK, Dunn JA, et al. Factors influencing blood transfusion during adult liver transplantation. Ann R Coll Surg Engl 1993; 75: 339-44.
2 Palomo Sanchez JC, Jimenez C, Moreno Gonzalez E, et al. Effects of intraoperative blood transfusion on postoperative complications and survival after orthotopic liver transplantation. Hepatogastroenterology 1998; 45: 1026-33.

3 Spahn DR, Casutt M. Eliminating blood transfusions. Anesthesiology 2000; 93: 242-55.

4 Cacciarelli TV, Keeffe EB, Moore DH, et al. Effect of intraoperative blood transfusion on patient outcome in hepatic transplantation. Arch Surg 1999; 134: 25-9.

5 Cancemi E, Ramsay KJ, Ramsay MAE, et al. Liver transplantation and blood use: predictors and impact on outcome. Anesthesiology 1999; 89; A419 (abstract).

6 Schroeder RA, Johnson LB, Plotkin JS, et al. Total blood transfusion and mortality after orthotopic liver transplantation (Letter). Anesthesiology 1999; 91: 329-30.

7 Steib A, Gengenwin N, Freys G, Boudjema K, Levy S, Otteni JC. Predictive factors of hyperfibrinolytic activity during liver transplantation in cirrhotic patients. Br J Anaesth 1994; 73: 645-8.

8 Hendriks HG, van der Meer J, Klompmaker IJ, et al. Blood loss in orthotopic liver transplantation: a retrospective analysis of transfusion requirements and the effects of autotransfusion of cell saver blood in 164 consecutive patients. Blood Coagul Fibrinolysis 2000; 11(Suppl. 1): 87-93.

9 Findlay JY, Rettke SR. Poor prediction of blood transfusion requirements in adult liver transplantations from preoperative variables. J Clin Anesth 2000; 12: 319-23.

10 Gerlach H, Gosse F, Rossaint R, Bechstein WO, Neuhaus $P$, Falke KJ. Die relevanz perioperativer gerinnungsparameter für die indikation von bluttransfusionen (German). Anaesthesist 1994; 43: 168-77.

11 Ozier YM, Le Cam B, Chatellier GI, et al. Intraoperative blood loss in pediatric liver transplantation: analysis of preoperative risk factors. Anesth Analg 1995; 81: 1142-7.

12 Dalmau A, Sabaté A, Acosta F, et al. Tranexamic acid reduces red cell transfusion better than - aminocaproic acid or placebo in liver transplantation. Anesth Analg 2000; 91: 29-34.

13 Porte RJ, Molenaar IQ Begliomini B, et al. Aprotinin and transfusion requirements in orthotopic liver transplantation: a multicentre randomised double-blind study. EMSALT study group. Lancet 2000; 355: 1303-9.

14 O'Connor CJ, Roozeboom D, Brown R, Tuman KJ. Pulmonary thromboembolism during liver transplantation: possible association with antifibrinolytic drugs and novel treatment options. Anesth Analg 2000; 91: 296-9.

15 Laxenaire MC, Dewachter P, Pecquet C Allergic risks of aprotinin. Ann Fr Anesth Reanim 2000; 19: 96-104. 